\title{
Los refranes de la racionalidad en el Quijote: el refrán definitorio «al enemigo que huye, hacerle la puente de plata»

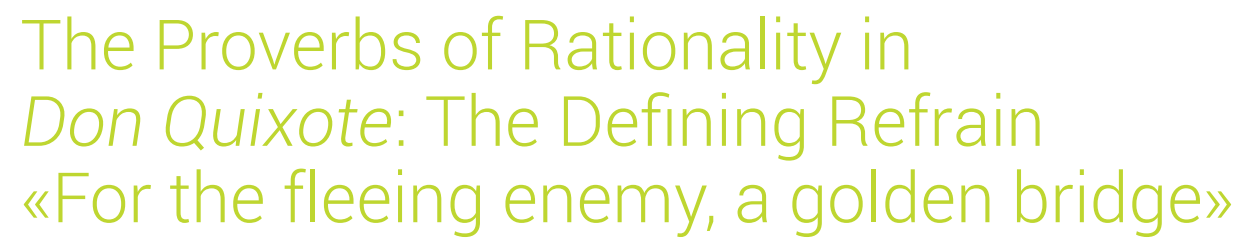

María del Carmen García Estradé

Sociedad Española de Estudios del Siglo XVIII ESPAÑA

garciaestrade@gmail.com

[Hipogrifo, (issn: 2328-1308), 6.2, 2018, pp. 117-130]

Recibido: 07-08-2017 / Aceptado: 05-09-2017

DOI: http://dx.doi.org/10.13035/H.2018.06.02.11

Resumen. El presente trabajo profundiza en los refranes de la racionalidad en el Quijote, cuyo estudio se expuso por primera vez en el XV Encuentro de Historiadores del Valle del Henares, Guadalajara 2016, donde se investigó el refrán argumentativo. Ahora, se siguen ampliando las funciones de los refranes en el Quijote y el estudio se centra en el refrán definitorio, teniendo en cuenta los siguientes aspectos: su definición (para qué sirve y cuál es su identidad), su clasificación y el análisis de un ejemplo significativo de uso en el Quijote: el refrán clasificado como autodefinitorio, «al enemigo que huye hacerle la puente de plata»; también se indaga su origen y su presencia en la literatura y en colecciones refranísticas. El refrán visualiza las relaciones habidas entre el Quijote cervantino y el de Fernández de Avellaneda, y la importancia de estas relaciones en la génesis y estructura de la Segunda parte del Quijote (1615).

Palabras clave. Refrán autodefinitorio; refrán en colecciones refranísticas; la tradición literaria del refrán; origen del refrán; Quijote de Cervantes (II parte) y el Quijote de Fernández de Avellaneda.

Abstract. The present work delves into the sayings of rationality in Don Quixote, whose study was first exposed in the XV Meeting of Historians of the Valley 
of Henares, Guadalajara 2016, where the argumentative saying was investigated. Now, the functions of the sayings in Don Quixote continue to be expanded and the study focuses on the definitional saying, taking into account the following aspects: its definition (what it serves for and what its identity is), its classification and the analysis of a significant example of use in Don Quixote: the proverb classified as self-defining, «For a fleeing enemy make a silver bridge», as well as its origin and presence in literature and refranísticas collections. The saying visualizes the relations between Cervantes Quixote and Fernández de Avellaneda, and the importance of these relations in the genesis and structure of the Second Part of Don Quixote.

Keywords. Self-defining refrain; Saying in refranísticas collections; Literary saying tradition; Origin of saying, Quijote, (II Parte) written by Cervantes and Quijote written by Fernández de Avellaneda.

\section{INTRODUCCIÓN}

«Nunca segundas partes fueron buenas», dice Cervantes por boca de Sansón Carrasco (Quijote, II, 4) y, aunque todos los refranes son verdaderos y este también lo es, hay otro que señala lo contrario: «la primera mujer escoba, la segunda señora»', el cual explica que las segundas nupcias suelen ser mejores que el primer casamiento, refrán con el que se pone de manifiesto la bondad de las segundas partes, sin que ambos refranes entren en contradicción, porque cada uno atiende a diferentes situaciones que pueden darse en la realidad.

Así, este pequeño preludio sobre la verdad de los refranes opuestos sirve para introducir el presente estudio, segunda parte de «Los refranes relativos a la racionalidad en El Quijote: el refrán argumentativo», que no por ser segunda parte debe ser menor en calidad y bondad a aquella otra primera parte, presentada en Guadalajara en 2016, en el XV Encuentro de Historiadores del Valle del Henares, con el título citado, que estudiaba, en concreto, el refrán argumentativo; y aún hay que añadir que esta Segunda Parte lleva incluidos en la piedra de toque del refrán, pedacitos de oro que iluminan la construcción y génesis de la Segunda Parte del Quijote cervantino. Solo por esto merece ya la atención del lector y del devoto quijotista. Trata, pues, este estudio de profundizar en los refranes de la racionalidad, presentando ahora el refrán definitorio.

\section{EL REFRÁN DEFINITORIO}

El refrán definitorio es el que pertenece, junto al refrán argumentativo y al refrán valorativo, al grupo de los refranes de la racionalidad, por ser la razón el fundamento de su existencia. Su función es revelar la identidad (de un personaje, animal, objeto, situación o acto); de ahí, la constante presencia del verbo ser, el verbo por excelencia que manifiesta la identidad. El refrán definitorio se presenta en dos ver- 
siones: la de revelar al ser por entero o a algunas de las partes que lo constituyen. De este modo, el refrán definitorio a través de su caracterización general -la pertenencia al grupo de los refranes de la racionalidad-y de su diferencia específica -la función de revelar la identidad - se emplea en la construcción del personaje ya sea en su retrato, en su etopeya o en su prosopografía.

La clasificación del refrán definitorio establece dos grupos, según el criterio de la relación entre el emisor que enuncia el refrán y el destinatario a quien se aplica el refrán: el refrán autodefinitorio, aquel en el que el emisor se aplica el refrán a sí mismo; y el refrán heterodefinitorio, por el cual el emisor aplica el refrán a otro.

Por el criterio de a quien se aplica el refrán, con independencia del emisor, el refrán se divide en refrán definitorio de persona, de animales, de objetos y de situaciones.

El Quijote de Cervantes ofrece gran variedad de representaciones del refrán definitorio. Se pueden encontrar ejemplos de los grupos aquí enunciados, el refrán autodefinitorio y el refrán heterodefinitorio. Se expone, a continuación, solo un caso significativo que atañe al refrán autodefinitorio de persona, «al enemigo que huye, hacerle la puente de plata» en el que don Quijote se define a sí mismo.

\section{«AL ENEMIgo QUE HUYE, HACERLE LA PUENTE DE PLATA» (QUIJOTE, II, 58, DQ, RA²)}

El episodio que da pie a la enunciación del refrán por don Quijote se inicia en un motivo de agradecimiento, cuyo defecto contrario, el ser desagradecido, lo valora el narrador del Quijote como más pernicioso que el pecado de soberbia. Agradecido por la comida ofrecida a él y a su escudero por los vecinos de un pueblo que, vestidos de pastores, representan la Arcadia feliz, don Quijote promete estar dos días naturales a la vera del camino, proclamando la belleza de las pastoras y retando a quien ose discutirlo a un desafío. Apostado en el camino queda, cuando llega una manada de toros bravos, conducida por hombres armados, que le avisan del peligro y le piden que se aparte; sin hacerles caso, temerario, se mantiene firme y los toros derriban a don Quijote y a Sancho, con sus caballerías, como si se tratase de un encierro de los sanfermines pamplonicas. De nuevo en pie, el caballero, al ver que no se detienen, decide perseguirlos, mostrando así su ánimo belicoso y su cólera, gritando: «-¡Deteneos y esperad, canalla malandrina, que un solo caballero os espera, el cual no tiene condición ni es de parecer de los que dicen que al enemigo que huye, hacerle la puente de plata!».

El refrán «se utiliza cuando alguien facilita la huida del adversario sin ensañarse con él. Más frecuentemente se emplea para expresar satisfacción por perder de vista a quien es poco grato» ${ }^{3}$, pero don Quijote no sigue el consejo, sino todo lo contrario: frente a la autoridad del refrán, él opone la suya y no emplea el refrán con función argumentativa, como es lo frecuente, sino con función definitoria, para de-

2. Significado de las abreviaturas, en cuanto a la localización del refrán (lugar en que se inserta), el personaje que lo enuncia y la clasificación del refrán: II, 58: Segunda parte del Quijote, cap. 58; DQ: don Quijote; RA: Refrán Autodefinitorio.

3. Suazo Pascual, 1999, p. 72. 
finirse a sí mismo, en una definición negativa, «un solo caballero os espera, el cual no tiene condición ni es de parecer de los que dicen», donde bien a las claras opera el verbo ser, propio de la definición.

Pero, ¿quiénes son, entonces, los que dicen este refrán y siguen su consejo? Un año antes de que lo pronuncie el Quijote cervantino, aparece documentado, en 1614, en el Quijote de Fernández de Avellaneda. Y no se referencia una única vez, sino que se cita por tres veces: en la pelea con el melonero de Ateca (cap. 6); en el episodio del ataharre del labrador (cap. 27), y en la batalla de Sancho con el escudero negro del rey de Chipre, el gigante Bramidán de Tajayunque, enemigo de don Quijote con quien tiene pendiente un desafío, que imitan los escuderos respectivos (cap. 33). En las dos primeras ocasiones, el refrán es pronunciado por don Quijote, y, en la tercera, está a cargo de Sancho. En los tres ejemplos se usa con función argumentativa para apoyar con la autoridad del refrán las decisiones tomadas 4 .

La primera aparición del refrán se produce cuando camino de Zaragoza, llegan amo y escudero a la localidad de Ateca, próxima a Calatayud y no lejos de Ariza, donde don Quijote ha colgado, en la plaza, un desafío firmado por el Caballero Desamorado. En aquel lugar, se topan con un melonar guardado por un hombre, al pie de su cabaña ${ }^{5}$, al que don Quijote confunde, en su disparatada imaginación, con Orlando el Furioso ${ }^{6}$ y decide entrar en batalla con él para ganar honra y llegar a Zaragoza, con su cabeza clavada en su lanza y obtener la admiración y pleitesía de todos. Así, pues, se interna en el melonar a caballo, pisoteando Rocinante matas y melones; sin atender los dos avisos del guarda, impertérrito, don Quijote sigue avanzado, ahora a pie y lanza en ristre, por lo que el melonero, en defensa de su hacienda, le arroja una primera piedra con honda que le golpea el brazo izquierdo y una segunda que le da en los pechos y lo derriba de espaldas por tierra; el guarda, asustado, huye, creyéndolo muerto y don Quijote se siente ganador de la batalla?:

-Dame, Sancho la mano, pues ya he salido con muy cumplida victoria; que para alcanzarla, bástáme que mi contrario haya huído de mí y no ha osado aguardarme, y el enemigo que huye, hacerle la puente de plata, como dicen. Dejémosle,

4. García Estradé, 2016, pp. 651-665.

5. Este episodio ha sido resaltado por Azorín, en el capítulo «El otro Quijote» (p. 171) de su libro Con permiso de los cervantistas. Uno de los tres rasgos principales del Quijote de 1614, advierte que es «un conocimiento de la vida de los pueblos y del campo». Y añade: «En él se escribe todo un capítulo sobre la lucha del héroe con el guarda de un melonar. Y en este melonar se ve una «cabaña», para estar día y noche guardándolo. Hay chozas de esa índole en los melonares levantinos».

6. Orlando el Furioso es el caballero protagonista de Espejo de caballerías, que, según explica don Quijote, «fue encantado por un moro y llevado a que guardase y defendiese la entrada de cierto castillo, por ser el caballero de mayores fuerzas del universo; encantándole el moro de suerte que, por ninguna parte puede ser herido ni muerto, si no es por la planta del pie». Este último dato recuerda a Aquiles, que solo era vulnerable por su talón (de ahí la expresión «el talón de Aquiles»), pues su madre lo sumergió en una laguna que daba la inmortalidad, agarrándolo por el talón que no fue mojado por estas aguas prodigiosas. Un relato hindú describe el mismo mito en un joven que solo podía ser herido por la cintura, que, al estar cubierta con una guirnalda de flores, no había recibido la luz de la inmortalidad,

7. Se sigue, para el Quijote de Fernández de Avellaneda, la edición de Martín de Riquer (1972) y se consulta también la de Luis Gómez Canseco (2000). 
pues, ir; que ya vendrá tiempo en que yo le busque y, a pesar suyo, acabemos la batalla comenzada.

La batalla comenzada se continúa en una segunda parte, cuando el melonero vuelve acompañado con otros hombres y al ver a sus contrarios descansando en la cabaña les muelen a palos. En este episodio, don Quijote y Sancho pierden sus jumentos, recogidos por el melonero como compensación por los daños ocasionados.

La segunda presencia del refrán tiene lugar en una venta, durante el ensayo de una comedia de Lope de Vega, Testimonio vengado, presenciado por don Quijote, quien, encolerizado por ver sin defensa a la reina, calumniada de adulterio por su hijo, interrumpe la representación y reta en desafío al príncipe. Este lo acepta y - aquí entra en juego el ataharre - le entrega un ataharre que había por allí, como prenda de su compromiso, no sin antes transformarlo en preciosísima liga suya. El caballero admite el hecho a pie juntillas. Pero el ataharre es de un labrador; furioso por ver hurtada su pertenencia, se la arrebata a don Quijote y huye, después de tirarle de espaldas al suelo de un empujón y de haber cinchado la cabeza de Sancho, que corre tras él citándole a un gracioso desafío, a imitación del que acaba de realizar su amo al cómico. Y don Quijote lo frena:

- Aguarda, aguarda, descomunal arriero y verás si te hago confesar, mal que te pese, que eres mejor que yo, con ser un grandísimo bellaco, puto e hijo de otro tal.

Don Quijote le dio voces, diciendo:

-Vuélvete, hijo Sancho, y déjale ir, que harto trabajo lleva consigo, pues como infame ha huido de la batalla sin osar atendernos; pero ¿qué ha de osar atender un sandio tal cual él es? Y ya te he dicho muchas veces que al enemigo que huye, la puente de plata, y si nos lleva la preciosa liga, no hay que espantar dello, porque muchos ladrones yo he leído en libros que han robado a caballeros andantes no solo a sus preciados caballos, sino también sus ricas armas, ropas y joyas.

El refrán se formula en una versión diferente a la anterior, más sintética, pues se elimina el verbo hacerle.

Se manifiesta el refrán, por tercera vez, en un episodio protagonizado en esta ocasión por Sancho, quien lo pronuncia a propósito del desafío pendiente con el escudero negro del rey de Chipre; pero deciden dejarse de peleas y, concertadas las paces, las sellan humorísticamente con un darse los pies, en vez de las manos, como procede según la costumbre, lo que aprovecha su contrincante para agarrar a Sancho del pie, tirarle al suelo y, burlándose de él, salir huyendo. Don Quijote acude a su lado para levantarlo, como tantas veces ha hecho Sancho con él y le dice estas palabras:

- Mucho siento tu desgracia, Sancho, pero puédeste alabar de que quedas vencedor y de que a traición y sobre treguas, y lo que peor es, huyendo, ha hecho 
tu contrario esta alevosía. Pero si quieres te lo traiga aquí para que te vengues, dilo; que iré por él hecho un rayo.

-No, jcuerpo de tal! - dijo Sancho-, pues peor librara si peleáramos mano a mano, y como v. m. dice, al enemigo que huye, la puente de plata.

El desafío de los escuderos es una parodia del desafío de sus amos. Sancho, como los criados de las comedias de capa y espada repiten en clave de humor los amores de su amo, remeda también en clave humorística los desafíos de su amo y señor, don Quijote. Así, pues, el episodio termina con Sancho burlado, a imitación de cómo queda burlado su amo en los desafíos que emprende, y con un refrán, «al enemigo que huye, la puente de plata», que deja a un lado la venganza y que también pronuncia Sancho, imitando a don Quijote, en un proceso de quijotización.

\section{ORIGEN DEL REFRÁN «AL ENEMIGO QUE HUYE, HACERLE LA PUENTE DE PLATA»}

La frase se atribuye al «Gran Capitán», don Gonzalo Fernández de Córdoba (1453-1515), - glorioso militar en el reinado de los Reyes Católicos-, como lo atestiguan varios autores desde el siglo XVI al XXI8. Sin embargo, Rodríguez Marín, que tantos esfuerzos dedicó a la paremiología, cuando realiza la edición anotada del Quijote pasa de largo ante este refrán sin dedicarle una explicación a su significado ni a su origen ${ }^{9}$.

El apodo de «Gran Capitán» será explicado por un personaje del Quijote, el cura. Es curioso constatar que, en la maletilla de libros, atada con una cadenilla, del ventero (I, 32), entre los de caballerías, hay uno titulado Historia sobre los hechos del Gran Capitán, Gonzalo Hernández de Córdoba, con la vida de Diego García de Paredes, lo que da ocasión a conocer la causa del apodo: «por sus muchas y grandes hazañas mereció ser llamado de todo el mundo "Gran Capitán", renombre famoso y claro y de él solo merecido». En efecto, por sus victorias, el «Gran Capitán», obtuvo el título de duque de Santángelo.

Este episodio, además de darnos a conocer el apodo, sirve para contraponer la mentira, representada por los fingidos libros de caballerías, y la verdad, presente en los históricos, e indica los gustos literarios del pueblo, según la gente allí reunida. El ventero no duda en despreciar los libros históricos: «Dos higas para el Gran Capitán y para ese Diego García que dice». Y ante la quema de libros de caballerías que se habla de hacer, no vacila en la elección de cuál debe ir al fuego: «Mas si alguno quiere quemar, sea ese del Gran Capitán y de ese Diego García, que antes dejaré quemar un hijo que ninguno de esotros».

Hoy día, en la Plaza de las Tendillas de Córdoba - que debe su nombre a las numerosas y pequeñas tiendas ubicadas junto a las casas de la Orden de Calatra-

8. Clemencín, 1947, p. 1845; Santa Cruz, Floresta española de apotegmas, 2. ${ }^{a}$ parte, cap. 3. ${ }^{\circ}$; Iribarren, 1996, p. 304; Suazo Pascual, 1999, p. 724; Buitrago, 2008, pp. 7 y 8; Cantera Ortiz de Urbina, 2011, p. 127. 9. Rodríguez Marín, 1948, tomo VIII, pp. 296 y 297; 1957, tomo VIII, pp. 73 y 74. 
va, en las inmediaciones del antiguo foro romano de la capital-, la ciudad le rinde honores en una estatua ecuestre que representa al invicto militar. El monumento al «Gran Capitán» es obra de Mateo Inurria (Córdoba 1857-Madrid 1924) y su traslado a la plaza, donde ahora se erige, se efectuó en 1927.

Otro origen se menciona en Apotegmas, de Erasmo. La frase se asigna a don Alonso de Aragón, hijo natural de don Juan II de Aragón y de doña Leonor de Escobar. Ayudó a su padre en la lucha contra los catalanes y consiguió una sonada victoria junto al río Besós, en 1471, haciendo que huyeran las tropas enemigas ${ }^{10}$.

Se ha atribuido también el refrán a Temístocles quien, una vez vencido el rey Jerjes, no permitió a sus soldados que destruyeran el puente por donde podía pasar el ejército enemigo, diciendo que era mejor dejarles huir que obligarles a combatir a la desesperada, según relata Sebastián de Horozco en su Libro de proverbios ${ }^{11}$. En las tres versiones, su procedencia es, claramente, militar.

Otra explicación sobre su origen señala una fuente árabe, encontrada en un poema, donde se lee: «Al enemigo se hacen puentes de plata», para valorar la importancia de la paz sobre la guerra y de la amistad sobre la enemistad, según registra Francisco Gurmendi en Doctrina física y moral de príncipes (1615), citado por Adolfo de Castro en su obra Estudios prácticos de buen decir y arcanidades del habla española (1880) 12

\section{LA TRADICIÓN LITERARIA DEL REFRÁN «AL ENEMIGO QUE HUYE, HACERLE LA PUENTE DE PLATA»}

El refrán se presenta mencionado por Cervantes en otras obras suyas. En una comedia, El gallardo español, impresa en 1615, que trata sobre la heroica defensa de Orán, Mazalquivir y el fuerte San Miguel por los españoles ante el ataque de los reyes de Argel, donde se mezcla la historia ${ }^{13}$ con las intrigas amorosas. El refrán es pronunciado por uno de los reyes de Argel, Alabez.

No se usa el refrán para seguir su consejo - como indica Bizarri14-, sino para todo lo contrario, pues un personaje expresa que a los que huyeron a Mazalquivir, no se les va a dejar tranquilos, hasta que entreguen la vida, como muestran estas palabras: «Roama: Fuéronse a Mazalquivir / algunos que se escaparon», a lo que contesta, declarando su intención de perseguirlos, el otro moro, Azán: «Algún tanto dilataron / esos perros el vivir», e, inmediatamente, Alabez pronuncia el refrán: «De esta huida no se arguye / el refrán que el vulgo trata / que es hacer puente de plata

\footnotetext{
10. Cantera Ortiz de Urbina, 2011, p. 127

11. Bizarri, 2015, pp. 210-211.

12. Iribarren, 1996, p. 304.

13. Sevilla Arroyo, editor del Teatro completo de Cervantes, considera que el dramaturgo se documentó en fuentes historiográficas fidedignas: Descripción general de África, de Mármol y Carvajal, y Diálogo de las guerras de Orán, de Baltasar de Morales.

14. «En El gallardo español, Cervantes lo utiliza con el sentido propio de 'facilitar la huida al enemigo'», en Diccionario de paremias cervantinas (Bizarri, 2015, p. 211).
} 
/ al enemigo que huye» (Jornada III, p. 364). Aunque choca un poco que un refrán castellano sea enunciado por un moro, recuérdese la fuente árabe existente sobre su origen y téngase presente el cautiverio de Cervantes por estas tierras, y su viaje a Orán en 1581, por encargo de Felipe II, donde pudo haber oído y comprendido el refrán.

La otra mención del refrán aparece en Los trabajos de Persiles y Sigismunda en boca de Periandro, cuando se dirige al caballero polaco para persuadirle de que no vaya tras su mujer, que se ha fugado con su dinero, las perlas y el amante, dejándole abandonado; primero le argumenta con el cuento de la serpiente criada en el seno del hombre, que se escapó y, luego, añade el refrán:

[el labrador] no la halló [la serpiente] porque se había ido; el cual, sin agradecer esta merced al cielo, quiso irla a buscar y volverla a anidar en su casa y en su seno, no mirando ser suma prudencia no buscar el hombre lo que no le está bien hallar, y, a lo que comúnmente se dice, que al enemigo que huye, la puente de plata, y el mayor que el hombre tiene suele decirse que es la mujer propia (Libro III, cap. 7, p. 311).

El refrán documenta su presencia en obras literarias castellanas en el siglo XVI. Rufo en Las seiscientas apotegmas y otras obras en verso, lo usa en la apotegma 321 con función argumentativa y como salida ingeniosa en la respuesta de un interlocutor desconocido a un joven con ligera cojera desde su nacimiento, situación a la que intenta quitar importancia, «pues para esperar le sobraban pies y para huir nunca los había de haber menester. "¿Y para alcanzar?" preguntó el susodicho. Respondió: "La puente de plata"». Alberto Blecua, editor de la obra de Rufo, comenta en la nota 4: «Alude al refrán "Enemigo que huye, la puente de plata"».

También este refrán se encuentra en la obra, La estrella de Sevilla (Acto II, esc. 6), de Lope de Vega. El rey, Sancho el Bravo ha entrado embozado en la casa de Busto Tavera, hombre principal, por gozar de su hermana Estrella («la Estrella de Sevilla»); al ser reconocido, el rey declara su identidad, pero Busto hace que no lo cree y mediante esta estratagema defiende los valores pisoteados por el rey, puesto que no puede ser el rey quien hace villanías y ofende así el honor de sus súbditos; este encuentro, al amenazar el rey con su espada a Busto, desemboca en una pelea, a cuyo alboroto acuden los criados de la casa y el rey aprovecha para huir sin ser conocido. Un criado quiere perseguirlo, pero Busto lo impide:

$$
\begin{array}{ll}
\text { Un CRIADO } & \begin{array}{l}
\text { Huyó quien tu afrenta trata. } \\
\text { Seguidle, dadle el castigo... }
\end{array} \\
\text { Busto } & \begin{array}{l}
\text { Dejadle, que al enemigo } \\
\text { se ha de hacer puente de plata. }
\end{array}
\end{array}
$$

Busto manda a sus criados que dejen paso libre al embozado, apoyando su decisión en un refrán, que es, en este caso, argumentativo, formulado en otra de sus versiones: «al enemigo se ha de hacer puente de plata». En conclusión, el refrán, con variantes, es el mismo que usa don Quijote en 1615, pero con funciones distintas en ambos casos. 
Las referencias literarias del Quijote de Fernández de Avellaneda, publicado en septiembre de 1614, ya han quedado mencionadas (caps. 6, 27 y 33).

Una nueva enunciación del refrán se halla en Segunda parte de la vida del Guzmán de Alfarache, atalaya de la vida humana (Lisboa, 1604), de Mateo Alemán. El protagonista se queda sin su esposa porque ha cambiado su amor por el de un capitán de galeras y, abandonado, discurre de esta manera: «Yo había oído decir que aquel era verdaderamente loco que buscaba su mujer habiéndosele ido, o que a el enemigo se le había de hacer la puente de plata por donde huyere» (p. 573).

Con igual intención, se utiliza aplicado a las relaciones matrimoniales, mal avenidas, en O'Donnell (cap. 5), uno de los Episodios Nacionales, de Pérez Galdós. Valeria, enfriado su amor por su marido, decide alejarlo de su lado, enviándolo a Filipinas con un alto cargo, propiciado por sus amistades y, como «mujer precavida, vale por dos», le prepara la ropa adecuada para ese país: «Todo lo adquirió la dama en las mejores tiendas y del género superior, por aquello de que al enemigo que huye, puente de plata».

El refrán se usa, en estos dos últimos ejemplos, con función argumentativa para justificar la decisión del marido de no ir tras su mujer, en Guzmán de Alfarache, y para apoyar, con evidente ironía y humor en O'Donell, que si el marido, equivalente del enemigo, huye a un destino lejano, se le debe tender el puente de plata, puente simbolizado, en este caso, por la ropa del género superior, comprada en las mejores tiendas. La función argumentativa es, igualmente, la propia del refrán de Lope de Vega, en un caso de honor y en los tres ejemplos del refrán en Avellaneda, sobre peleas entre los personajes encontrados al paso, episodios ya mencionados, e, incluso, es la función presente en Los trabajos de Persiles y Sigismunda.

Sin embargo, Cervantes, que emplea el mismo refrán que sus contemporáneos, lo hace en la Segunda Parte del Quijote con una función distinta: la función definitoria para que don Quijote se defina a sí mismo. Y tiene que ser así, porque después de la aparición del Quijote de Fernández de Avellaneda, en 1614, el Quijote cervantino tiene la obligación y la necesidad de dejar las cosas claras referentes a su identidad y de marcar las diferencias con el falso Quijote. Ya en la dedicatoria de sus Ocho Comedias y ocho entremeses nuevos, nunca representados, dirigida al conde de Lemos, descubre a su protector la preocupación, casi angustia, que le embargaba:

Don Quijote de la Mancha queda calzadas sus espuelas para besar los pies a V. E. Creo que llegará quejoso, porque en Tarragona le han asendereado y malparado, aunque, por sí o por no, lleva información hecha de que no es él el contenido en aquella historia, sino otro supuesto, que quiso ser él y no acertó a serlo.

Por esto, Cervantes aprovecha todas las ocasiones para proclamar a su don Quijote como el verdadero y al otro como un usurpador. Y se vale del refrán «al 
enemigo que huye, hacerle la puente de plata», estratégicamente situado al final de capítulo, para que su eficacia sea mayor ${ }^{15}$.

Estos son los pedacitos de oro del refrán que iluminan la construcción y génesis de la Segunda Parte del Quijote cervantino de que hablábamos en la Introducción. El refrán nos hace ver cómo se construye el Quijote cervantino en 1615 oponiéndose al de 1614.

\section{EL REFRÁN «AL ENEMIGO QUE HUYE, HACERLE LA PUENTE DE PLATA» EN LAS CO- LECCIONES REFRANÍSTICAS}

Las variantes de este refrán son bastantes en cuanto a su extensión y diversas por su formulación. Se pueden establecer tres grupos según esté el motivo de la huida manifestado con una imagen, con un verbo o suprimido. En un primer grupo, se intercala una imagen de carácter corporal, para expresar el motivo de la huida, «si vuelve la espalda». Así hace Hernán Núñez, en el siglo XVI: «al enemigo si vuelve la espalda la puente de plata»; Correas, en su Vocabulario de refranes y frases proverbiales (p. 29) también recoge la imagen en la misma versión: «Al enemigo, si vuelve la espalda, la puente de plata», y en esta forma llega al siglo XXI en el Diccionario de refranes, de Junceda.

En el segundo grupo, se manifiesta el motivo de la huida, expresado por el verbo, pero sin imagen, como en Pedro Vallés: «al enemigo si huye: la puente de plata», siendo esta una de las versiones citada por Fernández de Avellaneda. En Correas aparece en tres versiones: «Al enemigo, si huye, la puente de plata», «Al enemigo que huye, hacelle la puente de plata» y la versión anteriorrmente citada, en su Vocabulario de refranes y frases proverbiales (p. 29). En el siglo XXI, Campos/Barella ofrece la misma versión, sustituyendo la condicional por la relativa: «al enemigo que huye, la puente de plata» en el Diccionario de refranes ${ }^{16}$; una formulación casi igual, pero sin artículo delante de enemigo y de puente, recoge Buitrago: «A enemigo que huye, puente de plata» en su Diccionario de dichos y frases hechas ${ }^{17}$.

El tercer grupo presenta una versión más sintética, en la que se suprime el motivo de la huida, es la de Francisco de Espinosa: «Al enemigo puente de plata» (Refranero, p. 106) y la de Covarrubias: «Al enemigo la puente de plata» (s. v. enemigo, p. 780) ${ }^{18}$.

El significado del refrán es claro: «Se utiliza cuando alguien facilita la huida de un adversario en vez de ensañarse con él» ${ }^{19}$. Campos y Barella dice: «Enseña que en ciertas ocasiones conviene facilitar la huida al enemigo, o el desistimiento de quien nos estorba» (Diccionario de refranes, p. 1450). A esta idea, Buitrago añade otra: «Actualmente la frase se usa para expresar la satisfacción por perder de

15. García Estradé (1982) señala la importancia de los finales de capítulo, porque las ideas expuestas en ellos quedan impresas con más fuerza en la memoria.

16. Campos y Barella, 2001, p. 146.

17. Buitrago, 2008, p. 7.

18. También recoge Covarrubias, s. v. puente, «Al enemigo que se retira, la puente de plata» (p. 1380)

19. Suazo Pascual, 1999, p. 72 
vista sin esfuerzo o compromiso de parte de quien habla, a alguien desagradable o antipático»20; esta idea también la recoge Suazo Pascual: «Más cotidianamente se emplea cuando alguien expresa su satisfacción por perder de vista a alguien poco grato» ${ }^{21}$.

Don Quijote lo entiende en su sentido habitual, pero decide hacer lo contrario que aconseja el refrán y perseguir a sus adversarios, los toros bravos y sus conductores.

\section{CONCLUSIONES}

Del episodio analizado se pueden extraer las siguientes conclusiones:

1) Cervantes usa un refrán que sus contemporáneos (Fernández de Avellaneda, Mateo Alemán) ya habían incluido en sus obras antes de que él publicase la Segunda Parte del Quijote, en 1615, pero se distingue de ellos por usarlo con una función diferente: la función autodefinitoria en «al enemigo que huye, hacerle la puente de plata».

2) El refrán viene relacionado con una expresión, antepuesta o pospuesta, que indica su uso común por el pueblo, y le da su clasificación de refrán. Así lo escribe Cervantes: «[No soy de] los que dicen que» (Quijote, II, 58); «lo que comúnmente se dice» (Persiles, Libro III, cap. 7); «el refrán que el vulgo trata» (El gallardo español, jornada 3. ${ }^{\text {a) }}$; y en Fernández de Avellaneda: «como dicen» (Quijote, cap. 6); «como v. m. dice» (Quijote, cap. 33); no ocurre así en Lope de Vega ni en Rufo.

3) La aplicación del refrán analizado a las obras literarias mencionadas se realiza en diferentes campos semánticos, siendo el refrán «al enemigo que huye, hacerle la puente de plata», enunciado en las siguientes situaciones: en la guerra (El gallardo español); en disparatados desafíos (Quijote cervantino); en desafíos paródicos (Quiote de Fernández de Avellaneda); en casos de honor (La estrella de Sevilla) y en relaciones de matrimonios mal avenidos (Guzmán de Alfarache y O'Donnell).

4) El refrán utilizado por Cervantes coincide con las versiones más antiguas de los refraneros, cuales son las del marqués de Santillana (1508) y la de Hernán Núñez (1555), es decir, aquellas colecciones refranísticas que pudo leer Cervantes, antes de publicar su Quijote, Primera y Segunda Parte.

5) La presencia del refrán, «al enemigo que huye, hacerle puente de plata», aparecido en primer lugar en el Quijote de Fernández de Avellaneda (1614) y después en la Segunda Parte del Quijote cervantino (1615), muestra cómo Cervantes emplea un material, recogido en el Quijote de 1614, para construir un proceso literario propio, relevante, y diferente: la autodefinición de don Quijote, opuesto en su manera de actuar al Quijote de Fernández de Avellaneda.

De igual modo, el proceso de quijotización de Sancho en ciertos aspectos, en 1614 - con la imitación de los desafíos y del refrán citado-, pudo haberlo obser- 
vado Cervantes en su adversario, e insistiendo en este proceso, convertirlo en uno de los rasgos diferenciadores entre la Primera y la Segunda Parte del Quijote. La conclusión revela evidentemente que no hay imitación por parte de Cervantes, sino creación. Es, en cierta manera, una venganza, y un do de pecho, como si el escritor alcalaíno dijera al de Tordesillas: «Recojo materiales tuyos y los aprovecho no para beneficiarme de ellos en servil imitación, sino para manifestar la superioridad de mi ingenio y de mi invención», o quizás, la humildad de Cervantes, que es la de los verdaderos sabios, solo pretendía defender a su personaje, don Quijote, tan suyo, y a su obra de las intromisiones extrañas y remitirlos a su auténtica identidad.

\section{BibliografíA}

Alemán, Mateo, Guzmán de Alfarache, ed. Benito Brancaforte, Madrid, Akal, 1996.

Andino Sánchez, Antonio de Padua, Las fuentes grecolatinas en el «Quijote, tesis doctoral, Granada, Universidad de Granada, 2008.

Azorín, «El otro Quijote», en Con permiso de los cervantistas, Madrid, Visor Libros, 2005, pp. 71 y 72.

Bizarri, Hugo, Diccionario de paremias cervantinas, Alcalá de Henares, Universidad de Alcalá, 2015, pp. 210-211.

Buitrago, Alberto, Diccionario de dichos y frases hechas, Madrid, Espasa, 2008.

Calero Fernández, María Ángeles, La imagen de la mujer a través de la tradición paremiológica española (Lengua y cultura), tesis doctoral, Lérida, Estudio General de Lérida, 1990.

Campos, Juana G., y Barella, Ana, Diccionario de refranes, pról. de Rafael Lapesa, Madrid, Espasa, 2001.

Canellada, María Josefa, y Pallares, Berta, Refranero español, Madrid, Editorial Castilla, 2005.

Cantera Ortiz de Urbina, Jesús, Diccionario de refranes y frases hechas, Madrid, Abada Ediciones, 2011.

Cervantes, Miguel de, El ingenioso caballero don Quijote de la Mancha, Segunda Parte, ed. Diego Clemencín, Madrid, Editorial Castilla, 1947 y 1966.

Cervantes, Miguel de, El ingenioso caballero don Quijote de la Mancha, Segunda Parte, ed. Francisco Rodríguez Marín, Madrid, Espasa Calpe, 1957.

Cervantes, Miguel de, El ingenioso caballero don Quijote de la Mancha, Segunda Parte, ed. Francisco Rico, Edición del IV Centenario, Madrid, Real Academia Española/Asociación de Academias de la Lengua Española, 2005.

Cervantes, Miguel de, Los trabajos de Persiles y Sigismunda, ed. Isaías Lener e Isabel Lozano, Barcelona, Penguin Clásicos, 2015. 
Cervantes, Miguel de, El gallardo español, en Teatro Completo, ed. Florencio Sevilla Arroyo, Barcelona, Penguin Clásicos, 2016.

Cobarrubias Horozco, Sebastián de, Tesoro de la lengua castellana o española, ed. integral e ilustrada de Ignacio Arellano y Rafael Zafra, Madrid / Frankfurt am Main, Iberoamericana/Vervuert/Real Academia Española/Centro para la Edición de los Clásicos Españoles, 2006.

Correas, Gonzalo, Vocabulario de refranes y frases proverbiales, Madrid, Visor, 1992.

Espinosa, Francisco de, Refranero, Madrid, Real Academia Española, 1968.

Fernández de Avellaneda, Alonso, Segundo tomo del ingenioso hidalgo don Quixote de la Mancha, ed. Martín de Riquer, Madrid, Espasa Calpe, 1972.

Fernández de Avellaneda, Alonso, Segundo tomo del ingenioso hidalgo don Quixote de la Mancha, ed. Luis Gómez Canseco, Madrid, Biblioteca Nueva, 2000.

García Estradé, María del Carmen, «Contribuciones al estudio formal de Valle-Inclán. El análisis de los finales de capítulo en la trilogía carlista: paralelismos y correspondencias con las novelas esperpénticas», en II Simposio de Lengua y Literatura Españolas para Profesores de Bachillerato, 14,15 y 16 de mayo de 1981, Valencia, Gráficas Soler, 1982, pp. 223-249.

García Estradé, María del Carmen, «Los refranes relativos a la racionalidad en El Quijote: El refrán argumentativo», en XV Encuentro de Historiadores del Valle del Henares, ed. José Ramón López de los Mozos, Guadalajara, Aache Ediciones, 2016, pp. 651-665.

García Estradé, María del Carmen, «Los modismos religiosos en la paremiología española: un patrimonio inmaterial de la cultura cristiana», en Patrimonio inmaterial de la Cultura cristiana. XXI Simposio del Instituto Escurialense de Investigaciones Históricas y Artísticas, ed. de Javier Campos, El Escorial, Ediciones Escurialenses, 2013, pp. 119-146.

Iribarren, José María, El porqué de los dichos, Pamplona, Gobierno de Navarra, 1996. Junceda, Luis, Diccionario de refranes, Madrid, Espasa Calpe/BBVA, 2005, p. 27.

Martínez Kleiser, Luis, Refranero general ideológico español, Madrid, Editorial Hernando, 1972.

Panizo Rodríguez, Juliana, «La mujer en el Refranero», Revista de Folklore, 144, 1992, pp. 198-202. Disponible en: <http://espanaduero.es/> [consulta: 4 de abril de 2017].

Pérez Galdós, Benito, O'Donnell, Madrid, Historia 16, 1995.

Rufo, Juan, Las seiscientas apotegmas y otras obras en verso, ed. Alberto Blecua, Madrid, Espasa Calpe, 1972.

Santa Cruz, Melchor de, Floresta española de apotegmas, Madrid, Sociedad Española de Bibliófilos, 1953 [1574]. 
Suazo Pascual, Guillermo, Abecedario de dichos y frases hechas, Madrid, Edaf, 1999.

Vallés, Pedro, Libro de refranes copilado por el orden del ABC, ed. Melchor García Moreno, Madrid, Imprenta Alemana, 1917.

Vega, Félix Lope de, La estrella de Sevilla, en Obras, ed. y pról. Ángel Valbuena Prat, Barcelona, Vergara, 1963. 